\title{
Mating type markers reveal high levels of heterothallism in Leptographium sensu lato
}

Tuan A. Duong ${ }^{1 *}$, Z. Wilhelm de Beer $^{2}$, Brenda D. Wingfield ${ }^{1}$ and Michael J. Wingfield ${ }^{1}$

${ }^{1}$ Department of Genetics, ${ }^{2}$ Department of Microbiology and Plant Pathology, Forestry and Agricultural Biotechnology Institute (FABI), University of Pretoria, Pretoria 0002, South Africa.

* Corresponding author. Phone number: +27 (12) 420-3938; Fax: +27 (12) 420-3960; E-mail address: tuan.duong@fabi.up.ac.za (T.A. Duong); Postal address: Forestry and Agricultural Biotechnology Institute (FABI), University of Pretoria, Pretoria 0002, South Africa.

\begin{abstract}
Species of Leptographium sensu lato (Ophiostomatales, Ascomycetes) are sap-stain fungi vectored by bark beetles (Coleoptera, Scolytinae) and some species cause or are associated with tree diseases. Sexual states have been reported for more than 30 species in this group and these have been treated in the sexual genus Grosmannia. No sexual state is known for at least 59 additional species and these reside in the genus Leptographium. The discovery of sexual states for species of Leptographium relies mainly on the presence of fruiting bodies on host tissue at the time of isolation and/or intensive laboratory mating studies, which commonly have a low levels of success. In this study, markers were developed to diagnose mating-type and to study sexual compatibility of species in Leptographium sensu lato using these markers. To achieve this objective, available mating type sequences for species of Leptographium sensu lato and Ophiostoma were obtained, aligned and used to design primers to amplify MAT genes in Grosmannia and Leptographium species. Using these primers, it was possible to amplify portions of the mating type genes for 42 species and to determine thallism, in many species for the first time. Surprisingly, the results showed that heterothallic and putatively heterothallic species are abundant (39 out of 42 species) in Leptographium sensu lato, and only three species were confirmed to be homothallic. The mating-type markers developed in this study will be useful for future studies concerning mating type and sexual compatibility of species in this genus.
\end{abstract}

Keywords: Heterothallism, homothallism, Leptographium, Grosmannia, mating type markers. 


\section{Introduction}

Leptographium sensu lato is an ascomycete genus that includes both sexual and asexual species (De Beer and Wingfield, 2013). Species with known sexual states have been treated in the genus Grosmannia while those for which sexual states are unknown have been assigned names in Leptographium (Zipfel et al., 2006). There are currently 34 Leptographium sensu lato species with known sexual states. Of these, some have the ability to produce ascomata in cultures derived from single conidia or ascospores and are thus homothallic (Jacobs et al., 1998). Others are heterothallic and require crossing between isolates of opposite mating type to produce sexual structures (Duong et al., 2012; Jacobs et al., 1998; Masuya et al., 2005; Yamaoka et al., 2008). The remaining members of Leptographium sensu lato are known only by their asexual morphs.

Sexual compatibility in ascomycetes is determined by genes residing in the mating type (MAT) locus. The MAT locus has different alleles (idiomorphs) (Turgeon and Yoder, 2000), containing mating type genes that encode transcription factors controlling mate recognition and sexual processes (Metzenberg and Glass, 1990). In heterothallic ascomycetes, the mating types of isolates are determined by the presence of corresponding MAT idiomorphs in the haploid genome. Individuals of heterothallic ascomycetes have either the MAT1-1 or MAT1-2 idiomorph in their haploid genome and sexual reproduction occurs only when isolates of opposite mating type interact. In contrast, individual strains of homothallic ascomycetes contain both the MAT1-1 and MAT1-2 idiomorphs in their genomes and they are, therefore, self-fertile. While this is generally true, there are some exceptions, such as in the case of Ophiostoma quercus (Wilken et al., 2012).

The structure and gene content of the MAT loci have been used to gain insights into the sexual compatibility of many species originally believed to be asexual. Typically, most of these purported asexual species have been found to have fully-functional heterothallic mating systems (Kück and Pöggeler, 2009). Thus, mating-type markers have been developed for numerous important fungi and these have been used to determine whether sexual recombination might occur in natural populations of, for example, plant pathogens (Groenewald et al., 2006; Linde et al., 2003; Paoletti et al., 2005b; Wada et al., 2012). Mating type markers have also been useful to determine the mating type of individual isolates, thus replacing the traditionally tedious approach of crossing isolates in culture with tester strains of known mating type (Santos et al., 2010). Importantly, application of the growing knowledge regarding the MAT locus in fungi has facilitated the discovery of sexual cycles in many fungi 
of clinical or industrial relevance that were thought to be asexual (Horn et al., 2009; Seidl et al., 2009).

Mating type gene sequences and the structure of the MAT locus are known for ten species of Leptographium sensu lato (including Grosmannia). These include Grosmannia clavigera and its closely related species (Tsui et al., 2013), Leptographium procerum and L. profanum (Duong et al., 2013). The MAT loci of these species have structures typical of those of heterothallic ascomycetes with both of the $M A T$ idiomorphs present in an individual haploid genome. The MAT1-1 idiomorphs have three mating type genes namely MAT1-1-1, MAT1-12 and MAT1-1-3. But notably, besides the MAT1-2-1 gene, the MAT1-2 idiomorphs, all of these species have a truncated version of MAT1-1-1, lacking the functional alpha domain (Duong et al., 2013; Tsui et al., 2013). The presence of the truncated MAT1-1-1 on the MAT12 idiomorph has also been noted in species of Ophiostoma (Comeau et al., 2015; Tsui et al., 2013), a sister genus of Leptographium sensu lato, suggesting that the truncation event might share an evolutionary history among these two genera and perhaps also with other genera in the Ophiostomatales.

Most species in Leptographium sensu lato are known as only mitosporic fungi. Based on the results of Duong et al. (2013) and Tsui et al. (2013), we hypothesized that many of these species might actually have heterothallic mating systems. This would explain the low level of incidence of sexual states encountered for these fungi in nature or in culture. The aims of this study were thus to develop mating type markers in order to diagnose mating type and to consider the possible role that sexual reproduction might play in a relatively large collection of Leptographium sensu lato species.

\section{Material and methods}

\subsection{Cultures, growth conditions and DNA extraction}

Fungal isolates used in this study (Table 1) were obtained from the culture collection (CMW) of the Forestry and Agricultural Biotechnology Institute (FABI), University of Pretoria, South Africa. Single hyphal tip or single conidium cultures were grown in YM broth (2\% malt extract and $0.2 \%$ yeast extract) for 3 to 5 days. Mycelium was harvested by centrifugation and DNA was extracted using PrepMan ${ }^{\mathrm{TM}}$ Ultra reagent (Applied Biosystems, California, USA) following the methods described in Duong et al. (2012). 
Table 1. Fungal isolates used in this study, including GenBank accession numbers of partial sequences of the MAT1-2-1 and MAT1-1-3 genes. Mating types and thallism of isolates are also indicated. Abbreviations and symbols used in the table are explained in the footnote. Accession numbers of MAT sequences used in the phylogenetic analyses are printed in italic. Sequences generated in this study are printed in bold type.

\begin{tabular}{|c|c|c|c|c|c|c|c|}
\hline Species & Isolate number & Insect/Host & Origin & $\begin{array}{l}\text { Mating } \\
\text { type }\end{array}$ & MAT1-2-1 & MAT1-1-3 & Thallism \\
\hline G. aenigmatica & CMW2199 & Ips typographus japonicus & Japan & NA & KT779243 & KT779220 & $\mathrm{HO}$ \\
\hline \multirow[t]{4}{*}{ G. alacris } & CMW621 & Pinus pinaster & Portugal & MAT1-2 & KP171183 & & $\mathrm{HE}$ \\
\hline & CMW623 & Pinus pinaster & Portugal & MAT1-1 & & KP171181 & $\mathrm{HE}$ \\
\hline & CMW1136 & Pinus taeda & USA & MAT1-2 & KJ528492 & & $\mathrm{HE}$ \\
\hline & CMW2844 & Pinus pinaster & South Africa & MAT1-2 & KP171184 & & $\mathrm{HE}$ \\
\hline G. americana & CMW2980 & Larix sp. & $\mathrm{USA}$ & MAT1-2 & $K T 779263$ & & $\mathrm{P}-\mathrm{HE}$ \\
\hline \multirow[t]{2}{*}{ G. aurea } & CBS438.69 & $\begin{array}{l}\text { Pinus contorta var. } \\
\text { latifolia }\end{array}$ & Canada & MAT1-1 & & $J X 402951$ & $\mathrm{HE}$ \\
\hline & CMW29869 & Pinus contorta & Canada & MAT1-2 & $K T 779253$ & & $\mathrm{HE}$ \\
\hline \multirow[t]{2}{*}{ G. clavigera } & ATCC 18086 & Pinus ponderosa & Canada & MAT1-1 & & $J X 402948$ & $\mathrm{HE}$ \\
\hline & KW1407 & Pinus contorta & Canada & MAT1-2 & ACXQ02000048 & & $\mathrm{HE}$ \\
\hline \multirow[t]{5}{*}{ G. huntii } & CMW622 & $P$. pinaster & Portugal & MAT1-1 & & KT779227 & $\mathrm{HE}$ \\
\hline & CMW654 & Pinus sp. & USA & MAT1-2 & KT779250 & & $\mathrm{HE}$ \\
\hline & CMW1006 & Hylurgus ligniperda & New Zealand & MAT1-2 & $=\mathrm{KT} 779250$ & & $\mathrm{HE}$ \\
\hline & CMW1015 & Unknown & New Zealand & MAT1-1 & & $=\mathrm{KT} 779227$ & $\mathrm{HE}$ \\
\hline & CMW2824 & Pinus sp. & USA & MAT1-2 & $=\mathrm{KT} 779250$ & & $\mathrm{HE}$ \\
\hline \multirow[t]{2}{*}{ G. koreana } & CMW 14200 & Pinus densiflora & Korea & MAT1-2 & KT779247 & & $\mathrm{HE}$ \\
\hline & CMW14201 & Pinus densiflora & Korea & MAT1-1 & & $K T 779222$ & $\mathrm{HE}$ \\
\hline \multirow[t]{2}{*}{ G. piceiperda $\mathrm{B}^{*}$} & CMW452 & Pseudotsuga menziesii & USA & $\mathrm{NA}$ & $K T 779246$ & KT779224 & $\mathrm{HO}$ \\
\hline & CMW2811 & Picea rubens & USA & NA & $K T 779245$ & KT779223 & $\mathrm{HO}$ \\
\hline G. piceiperda $\mathrm{C}^{\ldots-}$ & CMW446 & Picea abies & Norway & $\mathrm{NA}$ & $K T 779244$ & $K T 779221$ & $\mathrm{HO}$ \\
\hline \multirow[t]{2}{*}{ G. robusta } & CMW710 & Unknown & Unknown & MAT1-1 & & $K T 779225$ & $\mathrm{P}-\mathrm{HE}$ \\
\hline & CMW34175 & Pinus ponderosa & USA & MAT1-1 & & $=\mathrm{KT} 779225$ & P-HE \\
\hline \multirow[t]{2}{*}{ G. serpens } & CMW191 & Pinus pinea & Italy & MAT1-1 & & $=\mathrm{KT} 779226$ & $\mathrm{P}-\mathrm{HE}$ \\
\hline & CMW192 & Pinus pinea & Italy & MAT1-1 & & $=\mathrm{KT779226}$ & P-HE \\
\hline
\end{tabular}




\begin{tabular}{|c|c|c|c|c|c|c|c|}
\hline Species & Isolate number & Insect/Host & Origin & $\begin{array}{l}\text { Mating } \\
\text { type }\end{array}$ & MAT1-2-1 & MAT1-1-3 & Thallism \\
\hline - & CMW289 & Pinus pinea & Italy & MAT1-1 & & $=$ KT779226 & P-HE \\
\hline & CMW290 & Pinus pinea & Italy & MAT1-1 & & $=$ KT779226 & P-HE \\
\hline & CMW304 & Pinus sylvestris & Italy & MAT1-1 & & KT779226 & P-HE \\
\hline G. yunnanensis & CMW5152 & Pinus yunnanensis & China & MAT1-2 & KT779249 & & $\mathrm{P}-\mathrm{HE}$ \\
\hline L. abieticolens & CMW2866 & Abies balsamea & USA & MAT1-1 & & KT779228 & P-HE \\
\hline L. abietinum & CMW2817 & Picea engelmannii & USA & MAT1-2 & KT779264 & & $\mathrm{P}-\mathrm{HE}$ \\
\hline L. albopini & CMW2065 & Pinus strobus & USA & MAT1-2 & KT779251 & & $\mathrm{P}-\mathrm{HE}$ \\
\hline L. alethinum & CMW 3767 & Hylobius abietis & $\mathrm{UK}$ & MAT1-1 & & KT779229 & $\mathrm{P}-\mathrm{HE}$ \\
\hline \multirow[t]{2}{*}{ L. bhutanense } & CMW 18650 & Pinus wallichiana & Bhutan & MAT1-1 & & KM491450 & $\mathrm{HE}$ \\
\hline & CMW18652 & Pinus wallichiana & Bhutan & MAT1-2 & KM491428 & & $\mathrm{HE}$ \\
\hline \multirow[t]{4}{*}{ L. castellanum } & CMW1988 & Hylurgus mickliki & Spain & MAT1-1 & & $=\mathrm{KT} 779231$ & $\mathrm{P}-\mathrm{HE}$ \\
\hline & CMW1989 & Hylurgus mickliki & Spain & MAT1-1 & & $=$ KT779231 & P-HE \\
\hline & CMW2320 & Pinus occidentalis & Dominican Rep. & MAT1-1 & & $=\mathrm{KT} 779231$ & P-HE \\
\hline & CMW2321 & Pinus occidentalis & Dominican Rep. & MAT1-1 & & KT779231 & P-HE \\
\hline L. celere & CMW12421 & Pinus semaonensis & China & MAT1-2 & $K T 779261$ & & $\mathrm{P}-\mathrm{HE}$ \\
\hline L. douglasii & CMW2076 & Pseudotsuga menziesii & USA & MAT1-1 & & $K T 779230$ & $\mathrm{P}-\mathrm{HE}$ \\
\hline \multirow[t]{2}{*}{ L. gibbsii } & CMW853 & Hylastes ater & UK & MAT1-2 & $=\mathrm{KT} 779258$ & & $\mathrm{P}-\mathrm{HE}$ \\
\hline & CMW1376 & Hylastes ater & UK & MAT1-2 & KT779258 & & P-HE \\
\hline \multirow[t]{2}{*}{ L. gracile } & CMW12316 & Pinus armandii & China & MAT1-2 & KM491429 & & P-HE \\
\hline & CMW12319 & Pinus armandii & China & MAT1-2 & KM491436 & & P-HE \\
\hline \multirow[t]{2}{*}{ L. longiclavatum } & CMW20606 & Picea glauca & Canada & MAT1-2 & $K T 779255$ & & $\mathrm{HE}$ \\
\hline & CMW20607 & Pinus contorta & Canada & MAT1-1 & & KT779232 & $\mathrm{HE}$ \\
\hline L. longiconidiophorum & CMW2004 & Pinus densiflora & Japan & MAT1-1 & & $K M 491452$ & $\mathrm{P}-\mathrm{HE}$ \\
\hline \multirow[t]{2}{*}{ L. lundbergii } & $\mathrm{CMW} 217$ & Pinus sylvestris & Sweden & MAT1-1 & & $K T 779233$ & $\mathrm{HE}$ \\
\hline & CMW2190 & Pinus sylvestris & Norway & MAT1-2 & $K T 779252$ & & $\mathrm{HE}$ \\
\hline L. manifestum & CMW12436 & Larix olgensis & China & MAT1-1 & & KT779234 & $\mathrm{P}-\mathrm{HE}$ \\
\hline L. pineti & CMW3837 & Pinus sp. & Indonesia & MAT1-1 & & $K T 779235$ & $\mathrm{P}-\mathrm{HE}$ \\
\hline
\end{tabular}




\begin{tabular}{|c|c|c|c|c|c|c|c|}
\hline Species & Isolate number & Insect/Host & Origin & $\begin{array}{l}\text { Mating } \\
\text { type }\end{array}$ & MAT1-2-1 & MAT1-1-3 & Thallism \\
\hline \multirow[t]{2}{*}{ L. pini-densiflorae } & CMW5157 & Pinus densiflora & Japan & MAT1-1 & & KM491453 & $\mathrm{HE}$ \\
\hline & CMW5162 & Pinus densiflora & Japan & MAT1-2 & KM491438 & & $\mathrm{HE}$ \\
\hline \multirow[t]{2}{*}{ L. procerum } & CMW45 & Pinus sylvestris & USA & MAT1-2 & $K C 883455$ & & $\mathrm{HE}$ \\
\hline & CMW216 & Pinus taeda & South Africa & MAT1-1 & & KC883456 & $\mathrm{HE}$ \\
\hline \multirow[t]{2}{*}{ L. profanum } & CMW 10552 & Carya sp. & USA & MAT1-2 & KC883457 & & $\mathrm{HE}$ \\
\hline & CMW10555 & Nyssa sylvatica & USA & MAT1-1 & & KC883458 & $\mathrm{HE}$ \\
\hline \multirow[t]{2}{*}{ L. pyrinum } & CMW169 & Pinus resinosa & USA & MAT1-2 & $K T 779262$ & & $\mathrm{HE}$ \\
\hline & CMW3889 & Pinus jeffreyi & USA & MAT1-1 & & KT779236 & $\mathrm{HE}$ \\
\hline L. sibiricum & CMW4481 & Abies sibirica & Russia & MAT1-2 & KM491443 & & $\mathrm{P}-\mathrm{HE}$ \\
\hline L. sinense & CMW38172 & Pinus elliottii & China & MAT1-2 & $K M 491433$ & & $\mathrm{P}-\mathrm{HE}$ \\
\hline \multirow[t]{2}{*}{ L. sinoprocerum } & CMW26230 & Pinus tabuliformis & China & MAT1-1 & & KM491460 & $\mathrm{HE}$ \\
\hline & CMW29990 & Pinus tabuliformis & China & MAT1-2 & KM491447 & & $\mathrm{HE}$ \\
\hline \multirow[t]{2}{*}{ L. terebrantis } & SS394 & $\begin{array}{l}\text { Pinus contorta } \\
\text { banksiana hybrid }\end{array}$ & Canada & MAT1-2 & $J X 402935$ & & $\mathrm{HE}$ \\
\hline & SS403 & Pinus contorta & Canada & MAT1-1 & & $J X 402956$ & $\mathrm{HE}$ \\
\hline \multirow[t]{2}{*}{ L. truncatum } & CMW644 & Hylastes $\mathrm{sp}$. & UK & MAT1-2 & KT779248 & & $\mathrm{HE}$ \\
\hline & CMW2402 & Pinus resinosa & Canada & MAT1-1 & & KT779237 & $\mathrm{HE}$ \\
\hline \multirow[t]{2}{*}{ L. wageneri v. ponderosae } & CMW279 & Pinus ponderosae & $\mathrm{USA}$ & MAT1-2 & $K T 779259$ & & $\mathrm{HE}$ \\
\hline & CMW307 & Pinus contorta & USA & MAT1-1 & & $=K T 779239$ & $\mathrm{HE}$ \\
\hline \multirow[t]{4}{*}{ L. wageneri v. pseudotsugae } & CMW1533 & Pseudotsuga menziesii & USA & MAT1-1 & & $=\mathrm{KT} \mathbf{T 7 9 2 3 9}$ & $\mathrm{HE}$ \\
\hline & CMW154 & Pseudotsuga menziesii & USA & MAT1-1 & & KT779239 & $\mathrm{HE}$ \\
\hline & CMW1541 & Pseudotsuga menziesii & USA & MAT1-1 & & $=$ KT779239 & $\mathrm{HE}$ \\
\hline & CMW2087 & Pseudotsuga menziesii & USA & MAT1-2 & KT779260 & & $\mathrm{HE}$ \\
\hline \multirow[t]{3}{*}{ L. wageneri v. wageneri } & CMW53 & Pinus ponderosa & USA & MAT1-2 & $=K T 779259$ & & $\mathrm{HE}$ \\
\hline & CMW493 & Pinyon Pine & USA & MAT1-1 & & KT779240 & $\mathrm{HE}$ \\
\hline & CMW1828 & Pinus edulis & USA & MAT1-1 & & $=K T 779240$ & $\mathrm{HE}$ \\
\hline L. wingfieldii & CMW2096 & Pinus sylvestris & France & MAT1-1 & & $J X 402949$ & $\mathrm{HE}$ \\
\hline
\end{tabular}




\begin{tabular}{|c|c|c|c|c|c|c|c|}
\hline Species & Isolate number & Insect/Host & Origin & $\begin{array}{l}\text { Mating } \\
\text { type }\end{array}$ & MAT1-2-1 & MAT1-1-3 & Thallism \\
\hline & CMW10221 & Pinus strobus & USA & MAT1-2 & KT779256 & & $\mathrm{HE}$ \\
\hline \multirow[t]{6}{*}{ L. yamaokae } & CMW1935 & Pinus sp. & Japan & MAT1-1 & & $=\mathrm{KT} 779241$ & $\mathrm{P}-\mathrm{HE}$ \\
\hline & CMW1944 & Pinus sp. & Japan & MAT1-1 & & =KT779241 & P-HE \\
\hline & CMW4726 & Pinus densiflora & Japan & MAT1-1 & & KT779241 & P-HE \\
\hline & CMW4727 & Pinus densiflora & Japan & MAT1-1 & & $=$ KT779241 & $\mathrm{P}-\mathrm{HE}$ \\
\hline & CMW4728 & Pinus densiflora & Japan & MAT1-1 & & =KT779241 & P-HE \\
\hline & CMW4729 & Pinus densiflora & Japan & MAT1-1 & & $=$ KT779241 & P-HE \\
\hline \multirow[t]{2}{*}{ Leptographium sp. X } & CMW 15470 & Pinus contorta & Canada & MAT1-2 & KT779257 & & $\mathrm{HE}$ \\
\hline & CMW15493 & Pinus contorta & Canada & MAT1-1 & & KT779242 & $\mathrm{HE}$ \\
\hline \multirow[t]{2}{*}{ O. novo-ulmi sub. novo-ulmi } & $\mathrm{H} 327$ & Ulmus sp. & Slovakia & MAT1-1 & & FJ858801 & $\mathrm{HE}$ \\
\hline & V19 & Ulmus sp. & Russia & MAT1-2 & AY887029 & & $\mathrm{HE}$ \\
\hline \multirow[t]{2}{*}{ O. quercus } & CMW27845 & Quercus sp. & Canada & MAT1-1 & & $J Q 319596$ & $\mathrm{HE}$ \\
\hline & CMW27847 & Quercus sp. & UK & MAT1-2 & FJ865429 & & $\mathrm{HE}$ \\
\hline
\end{tabular}

CMW = Culture Collection of the Forestry and Agricultural Biotechnology Institute (FABI), University of Pretoria, South Africa. NA = Not applicable; HE = Heterothallic; $\mathrm{HO}=$ Homothallic; $\mathrm{P}-\mathrm{HE}=$ Putative heterothallic. * = Isolates referred to as 'G. piceiperda $\mathrm{B}$ ' and 'G. piceiperda C' have been shown to represent distinct species in the G. piceiperda species complex (Linnakoski et al., 2012). 


\subsection{MAT primer design}

The sequences of MAT1-2-1 locus in G. clavigera and its relatives (Tsui et al., 2013), L. procerum, L. profanum (Duong et al., 2013), O. ulmi and O. novo-ulmi subsp. novo-ulmi (Paoletti et al., 2005a) were aligned and used to design primers to detect the MAT1-2 idiomorph. The primers, Oph-HMG1 (5'- CGYAAGGAYMAYCACAAGGC -3') and OphHMG2 (5'-GGRTGAAGMMKCTCAACCTG -3'), were designed to amplify part of the HMG domain from the MAT1-2-1 gene.

Because all the known MAT loci in Leptographium sensu lato have a truncated version of MAT1-1-1 in the MAT1-2 idiomorphs, we refrained from designing MAT1-1 primers from the MAT1-1-1 gene sequence. Primers Oph-MAT1F1 (5'-ATGKCCRATGARGAYTGCT -3') and Oph-MAT1R2 (5'- GGCGKTKGCRTTGTAYTTGTA -3') (Duong et al., 2015) were previously designed from the MAT1-1-3 gene, which appears to be commonly present in Leptographium sensu lato (Duong et al., 2013; Tsui et al., 2013) and other Ophiostoma spp. for which the full MAT locus has been characterized (Comeau et al., 2015; Tsui et al., 2013), for detection of the MAT1-1 idiomorph. In some species, where amplification with this primer combination failed, the primer Oph-MAT1F1 was used in combination with Oph-MAT1R1 (5'- GGCYYTRTGAAGYTTCTGTGC -3'), although this combination resulted in slightly shorter fragments.

\subsection{PCR amplification, sequencing and mating type assignment}

A PCR reaction mixture of $25 \mu 1$ consisted of $2.5 \mu 110 \times$ PCR reaction buffer, $2.5 \mathrm{mM}$ $\mathrm{MgCl}_{2}, 200 \mu \mathrm{M}$ each dNTP, $0.8 \mu \mathrm{M}$ of each primer (forward and reverse), $1 \mathrm{U}$ FastStart Taq DNA Polymerase (Roche) and 20 to $50 \mathrm{ng}$ of genomic DNA. The cycling conditions were an initial denaturation at $95^{\circ} \mathrm{C}$ for $5 \mathrm{~min}$, followed by 35 cycles of $95^{\circ} \mathrm{C}$ for $30 \mathrm{sec}, 55^{\circ} \mathrm{C}$ annealing for $30 \mathrm{sec}$, and $72{ }^{\circ} \mathrm{C}$ extension for $60 \mathrm{sec}$, with a final extension at $72{ }^{\circ} \mathrm{C}$ for $8 \mathrm{~min}$. In most cases, the annealing temperature was at $55^{\circ} \mathrm{C}$ for both $M A T 1-1$ and MAT1-2 primers. However, when the PCR failed or when non-specific amplification was observed, the annealing temperature was adjusted in the range of $52{ }^{\circ} \mathrm{C}$ to $60{ }^{\circ} \mathrm{C}$. Resulting PCR products were separated using $2 \%$ agarose gel electrophoresis, and gels were stained with GelRed (Biotium, Inc., California, USA) and examined under UV light.

The success of MAT marker amplification was confirmed by sequencing the obtained $P C R$ amplicons. In cases where a single product was obtained, the PCR products were treated with exonuclease I and shrimp alkaline phosphatase (Exo-SAP) (Fermentas Inc., Hanover, MD, 
USA) following the manufacturer's instructions, to remove excess primers and dNTPs. Where multiple bands were present, fragments of expected size were excised from the gel and sequenced using the same protocol. The treated or excised PCR products were directly sequenced using the same primers that were used for PCR amplification and the Big Dye ${ }^{\circledR}$ Terminator v. 3.1 cycle sequencing premix kit (Applied Biosystems, Foster City, California, USA).

Species that showed amplification products for both MAT1-1 and MAT1-2 primer combinations in a single isolate were designated as being homothallic. Species displaying amplification for both MAT1-1 and MAT1-2 primer combinations, but where only MAT1-1 or MAT1-2 could be detected in an individual isolate, were likewise designated as being heterothallic. Species where only the MAT1-2 or MAT1-1 idiomorph was detected were considered to be putatively heterothallic.

\subsection{Phylogenetic analyses}

In order to investigate the phylogenetic relationship between homothallic and heterothallic species investigated, phylogenetic analyses were conducted on a combined dataset of ITS2LSU, partial MAT1-2-1 and MAT1-1-3 genes. The ITS2-LSU sequences for all species were obtained from GenBank, representing type isolates of each species, sequence accession numbers for these are presented elsewhere (De Beer and Wingfield, 2013; Yin et al., 2015). Sequences for regions of MAT1-2-1 and MAT1-1-3 genes were generated as described above (Table 1). All there gene regions were combined and aligned using an online version of MAFFT v. 7 (Katoh and Standley, 2013) .

Maximum likelihood (ML) and Bayesian inference (BI) analyses were carried out on the aligned dataset. Maximum likelihood analysis was conducted using RaxML v8.1.15 (Stamatakis et al., 2005) applying GTR+G model. A ML search for best-scoring ML tree followed by one thousand rapid bootstrap analysis, was conducted. Bayesian inference analyses were performed using MrBayes v. 3.1.2 (Ronquist and Huelsenbeck, 2003) applying the same models as used in the ML analysis. Four MCMC chains were run simultaneously for 5 million generations and tree sampling was conducted after every $100^{\text {th }}$ generation. Twenty five percent of the trees sampled at the burn-in phase were discarded and posterior probabilities were calculated from the remaining trees. 


\section{Results}

\subsection{MAT primer design, PCR amplification and mating type assignment}

MAT1-2 and MAT1-1 primers were successfully used in PCRs to amplify portions of MAT12-1 and MAT1-1-3 genes respectively. Primers Oph-HMG1 and Oph-HMG2 amplified part of HMG box of MAT1-2-1 gene, resulting in PCR products of about $230 \mathrm{bp}$. Primers OphMAT1F1 and Oph-MAT1R2 amplified part of the MAT1-1-3 gene, resulting in PCR products of about $450 \mathrm{bp}$. In cases where this MAT1-1 primer combination failed to amplify, for example in G. aenigmaticum, 'G. piceiperda B' and 'G. piceiperda C', primers OphMAT1R1 were successfully used in place of Oph-MAT1R2, resulting in slightly shorter PCR products of the MAT1-1-3 gene. The relative primer binding positions on each of the MAT loci are presented in Fig. 1.



Figure 1. Relative binding sites of primers used to amplify MAT1-1 and MAT1-2 in this study. The organization of MAT locus presented in the figure was adapted from MAT loci in L. procerum and L. profanum.

In most cases, a single PCR product was obtained from each positive reaction. The identities of PCR products were confirmed as part of MAT1-2-1 or MAT1-1-3 genes by sequencing all positive amplifications. All obtained sequences were deposited in GenBank and accession numbers are presented in Table 1. Portions of the MAT genes for a total of 42 species residing in Leptographium sensu lato species were successfully amplified (Table 1). Based on the amplification profile, 20 species were identified as heterothallic, three species were homothallic and 19 species were tentatively assigned as heterothallic. Examples of MAT PCR amplification for some of the tested isolates are presented in Fig. 2. 


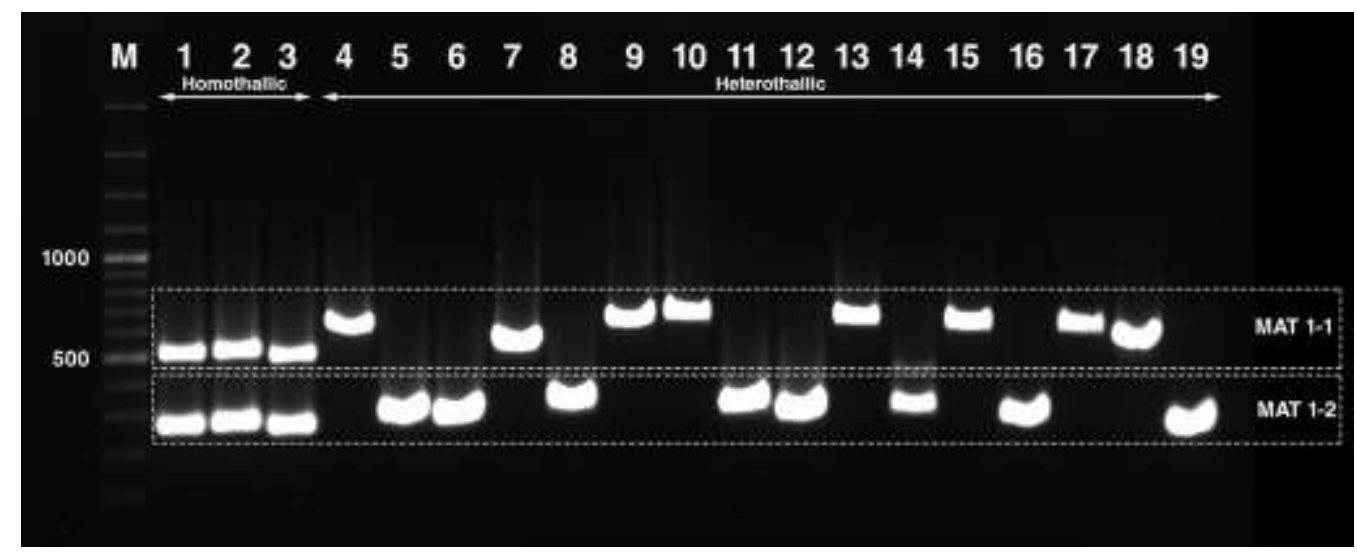

Figure 2. Agarose gel electrophoresis (2\% w/v) of MAT1-1-3 (larger size bands- around 500 bp) and MAT1-2-1 (smaller size bands, about $230 \mathrm{bp}$ ) PCR fragments from representative Leptographium sensu lato species. 'G. piceiperda C' CMW446 (1); G. aenigmatica CMW2199 (2); 'G. piceiperda B' CMW2811 (3); G. alacris: CMW623 (4), CMW621 (5); G. koreana: CMW14200 (6), CMW14201 (7); G. huntii: CMW1006 (8), CMW1015 (9); L. bhutanense: CMW18650 (10), CMW18652 (11); L. longiclavatum: CMW20606 (12), CMW20607 (13); L. wageneri var. wageneri CMW53 (14), CMW493 (15); L. wageneri var. ponderosae CMW279 (16), CMW307 (17); L. wageneri var. pseudotsugae CMW154 (18), CMW2087 (19). The molecular weight marker (M) used was GeneRuler ${ }^{\mathrm{TM}} 100$ bp Plus DNA Ladder (Fermentas), the 1000 and 500 bp size fragments are indicated on the figure.

\subsection{Phylogenetic analyses}

The alignment of the ITS2-LSU region contained 604 characters, of which 450 characters were constant and 114 characters were parsimony informative. The alignment of MAT1-1-3 gene region contained 493 characters, of which 191 characters were constant and 251 characters were parsimony informative. The alignment of MAT1-2-1 gene region contained 215 characters, of which 90 were constant and 121 were parsimony informative.

ML and BI phylogenetic analyses of the combined dataset of ITS2-LSU, partial MAT1-2-1 and MAT1-1-3 genes resulted in trees with similar topology. In most cases, the species investigated grouped together to form species complexes as defined by De Beer \& Wingfield (2013). Collectively, species from seven species complexes in Leptographium sensu lato were considered. Notably, three homothallic species as identified using MAT markers, $G$. aenigmatica, 'G. piceiperda B' and 'G. piceiperda C', resided in a single clade with high BI posterior probability and ML bootstrap support (Fig. 3). All the remaining species that were heterothallic or putatively heterothallic resided in six different species complexes (Fig. 3). These were the G. clavigera complex, L. lundbergii complex, G. wageneri complex, G. 




Figure 3. Phylogram derived from RaxML analysis of combined dataset of ITS2-LSU, MAT1-1-3 and MAT1-21 gene regions. Phylogenetic support is presented at nodes as Bayesian posterior probabilities $(\geq 0.95) / \mathrm{ML}$ bootstrap $(\geq 70)$. Homothallic species are marked with green circles, heterothallic species are marked with blue squares and putatively heterothallic species are marked with yellow squares. ITS-LSU GenBank accession numbers are presented next to the species name. GenBank accession numbers for MAT1-1-3 and MAT1-2-1 used in phylogenetic analyses are presented in italic in Table 1. 
serpens complex, L. procerum complex and G. penicillata complex. Of these, only the $G$. wageneri and G. penicillata complexes were well supported by BI and ML analyses.

\section{Discussion}

Molecular markers developed in this study made it possible to amplify and identify the mating strategy of 42 species residing in Leptographium sensu lato. Many species previously considered to be asexual were shown to be either heterothallic or putatively heterothallic, with individual isolates having only a single idiomorph. It will now be possible to attempt to induce sexual structures for these fungi in culture, by pairing isolates known to represent opposite mating types. Where this can be achieved, various genetic studies could also then be undertaken on these species that would otherwise not have been possible.

The lack of opposite mating type isolates in our possession negated the possibility for us to recover both MAT idiomorphs in a number of species included in this study. Thus, 19 species for which only MAT1-1 or MAT1-2 idiomorph could be recovered were designated as putatively heterothallic. With the MAT makers now available, it will be possible to confirm the heterothallic nature of these species when additional isolates become available for them. It is important to also recognize that primers described in this study could fail to amplify both MAT idiomorphs in some of these species and thus they could be homothallic. Although this is unlikely, the thallism of these species will need to be treated as putative until the opposite MAT idiomorphs to those detected in this study can be found.

Prior to this study, the mating types were known for only a small number of species residing in Leptographium sensu lato. Thus a particularly interesting outcome of this study was that the majority of species tested were either heterothallic or putatively heterothallic and this was in contrast to a relatively small number (three) of homothallic species detected. This finding is consistent with the fact that the greater number of species in Leptographium sensu lato have long been considered as asexual species (De Beer and Wingfield, 2013). Based on the results of this study, we believe that many species found only in the asexual form in nature are probably capable of reproducing sexually. It is plausible that their sexual states have not been seen due to their heterothallic nature and the fact that they have been collected in the absence of an opposite mating strain. This is similar to the situation for various other fungi, thought to be asexual but later shown to be heterothallic and where sexual states have recently been 
discovered for some of the species (Horn et al., 2009; O'Gorman et al., 2008; Seidl et al., 2009).

Duong et al. (2012) were able to show that G. alacris is heterothallic by randomly crossing different isolates in all possible combinations. Thus, of the five species in the G. serpens complex (Duong et al., 2012), sexual sates have been found only in the case of G. alacris. Efforts to induce sexual states in the other four species did not result in ascomata. The present study has provided molecular evidence confirming that G. alacris is heterothallic, as are the other species in the G. serpens complex (Duong et al., 2012). In the present study, only a single mating type was found for isolates of G. serpens (MAT1-1), L. castellanum (MAT1-1), L. yamaokae (MAT1-1) and L. gibbsii (MAT1-2) and it will not be possible to attempt to produce sexual structures until strains of opposite mating type have been found. The results of this study explain why these fungi failed to produce sexual states in the study by Duong et al. (2012).

Goheen and Cobb (1978) reported the discovery of a sexual state in the important conifer root pathogen G. wageneri, which was found in the galleries of Hylastes macer. This form of the fungus has never again been seen and there has been doubt as to whether these authors had possibly collected a sexual state of some other ophiostomatoid fungus (Harrington and Cobb, 1988). The results of our study show clearly that $G$. wageneri is a heterothallic fungus and thus has the capacity to undergo sexual outcrossing. This provides strong evidence to suggest that Goheen and Cobb (1978) correctly identified the ascomata of this fungus in nature. Thus, it serves as an interesting example of a Leptographium sp. for which a sexual state has been found in nature only once and could never be produced in the laboratory (Wingfield, unpublished).

Species in Leptographium sensu lato have been assigned to different complexes based on their relatedness in phylogeny, morphological characters, as well as their ecology (De Beer and Wingfield, 2013; Linnakoski et al., 2012). Results of the present study showed that those species belonging to the same complex consistently share the same mode of sexual reproduction. Likewise, the only three homothallic species ('G. piceiderda B', 'G. piceiperda $\mathrm{C}^{\prime}$ and G. aenigmatica) considered in this study grouped in a single, well supported clade, consistent with the G. piceiperda complex previously defined (De Beer and Wingfield, 2013; Linnakoski et al., 2012). This suggests that these species might share a common homothallic ancestor. The remaining 39 heterothallic (or putatively heterothallic species) reside in six different species complexes. A number of other species residing in these six species 
complexes could not be included in this study but based on the patterns observed, it is likely that they will also have a heterothallic mating system.

Patterns of distribution of sexual compatibility have previously been used to better understand the evolution of fungal mating systems in other fungi (Inderbitzin et al., 2005; Nygren et al., 2011; Yun et al., 1999). Likewise, the distribution of homothallic and heterothallic species provides an opportunity to gain insights into the origin and evolution of homothallism and heterothallism in Leptographium sensu lato. From the results of this study, it is reasonable to hypothesize that homothallism in G. piceiperda complex has evolved once from a heterothallic ancestor. A common heterothallic ancestor would thus best explain the current patterns of sexual compatibility in Leptographium sensu lato. However, the detailed structure of the MAT loci of species in the G. piceiperda complex, together with that in closely related heterothallic species such as those in the G. clavigera and L. lundbergii complexes, will be required to confirm this hypothesis.

\section{Acknowledgements}

This work was funded by members of the Tree Protection Co-operative Programme (TPCP) and the DST-NRF Centre of Excellence in Tree Health Biotechnology (CTHB) at the Forestry and Agricultural Biotechnology Institute (FABI), the National Research Foundation (NRF) and the University of Pretoria, Pretoria, South Africa. 


\section{References}

Comeau AM, Dufour J, Bouvet GF, Jacobi V, Nigg M, Henrissat B, Laroche J, Levesque RC, Bernier L, 2015. Functional annotation of the Ophiostoma novo-ulmi genome: insights into the phytopathogenicity of the fungal agent of Dutch elm disease. Genome biology and evolution 7, 410-430.

De Beer ZW, Wingfield MJ, 2013. Emerging lineages in the Ophiostomatales, in: Seifert, K.A., De Beer, Z.W., Wingfield, M.J. (Eds.), The Ophiostomatoid Fungi: Expanding Frontiers. CBS Biodiversity Series 12, Utrecht, The Netherlands, pp. 21-46.

Duong TA, de Beer ZW, Wingfield BD, Eckhardt LG, Wingfield MJ, 2015. Microsatellite and mating type markers reveal unexpected patterns of genetic diversity in the pine root-infecting fungus Grosmannia alacris. Plant Pathology 64, 235-242.

Duong TA, de Beer ZW, Wingfield BD, Wingfield MJ, 2012. Phylogeny and taxonomy of species in the Grosmannia serpens complex. Mycologia 104, 715-732.

Duong TA, de Beer ZW, Wingfield BD, Wingfield MJ, 2013. Characterization of the mating-type genes in Leptographium procerum and Leptographium profanum. Fungal Biology 117, 411-421.

Goheen DJ, Cobb FW, 1978. Occurrence of Verticicladiella wagenerii and its perfect state, Ceratocystis wageneri sp. nov., in insect galleries. Phytopathology 68, 1192-1195.

Groenewald M, Groenewald JZ, Harrington TC, Abeln ECA, Crous PW, 2006. Mating type gene analysis in apparently asexual Cercospora species is suggestive of cryptic sex. Fungal Genetics and Biology 43, 813-825.

Harrington TC, Cobb FW, 1988. Leptographium root diseases on conifers. APS press, St. Paul, Minnesota.

Horn BW, Ramirez-Prado JH, Carbone I, 2009. The sexual state of Aspergillus parasiticus. Mycologia 101, 275280.

Inderbitzin P, Harkness J, Turgeon BG, Berbee ML, 2005. Lateral transfer of mating system in Stemphylium. Proceedings of the National Academy of Sciences of the United States of America 102, 11390-11395.

Jacobs K, Wingfield M, Wingfield B, Yamaoka Y, 1998. Comparison of Ophiostoma huntii and O. europhioides and description of O. aenigmaticum sp. nov. Mycological Research 102, 289-294.

Katoh K, Standley DM, 2013. MAFFT multiple sequence alignment software version 7: improvements in performance and usability. Molecular Biology and Evolution 30, 772-780.

Kück U, Pöggeler S, 2009. Cryptic sex in fungi. Fungal Biology Reviews 23, 86-90.

Linde CC, Zala M, Ceccarelli S, McDonald BA, 2003. Further evidence for sexual reproduction in Rhynchosporium secalis based on distribution and frequency of mating-type alleles. Fungal Genetics and Biology 40, 115-125. 
Linnakoski R, Dee Beer ZW, Duong TA, Niemelä P, Pappinen A, Wingfield MJ, 2012. Grosmannia and Leptographium spp. associated with conifer-infesting bark beetles in Finland and Russia, including Leptographium taigense sp. nov. Antonie Van Leeuwenhoek 102, 375-399.

Masuya H, Kim JJ, Wingfield MJ, Yamaoka Y, Kaneko S, Breuil C, Kim GH, 2005. Discovery and description of a teleomorph for Leptographium koreanum. Mycotaxon 94, 159-173.

Metzenberg RL, Glass NL, 1990. Mating type and mating strategies in Neurospora. Bioessays 12, 53-59.

Nygren K, Strandberg R, Wallberg A, Nabholz B, Gustafsson T, García D, Cano J, Guarro J, Johannesson H, 2011. A comprehensive phylogeny of Neurospora reveals a link between reproductive mode and molecular evolution in fungi. Molecular Phylogenetics and Evolution 59, 649-663.

O’Gorman CM, Fuller HT, Dyer PS, 2008. Discovery of a sexual cycle in the opportunistic fungal pathogen Aspergillus fumigatus. Nature 457, 471-474.

Paoletti M, Buck KW, Brasier CM, 2005a. Cloning and sequence analysis of the MAT-B (MAT-2) genes from the three Dutch elm disease pathogens, Ophiostoma ulmi, O. novo-ulmi and O. himal-ulmi. Mycological Research 109, 983-991.

Paoletti M, Rydholm C, Schwier EU, Anderson MJ, Szakacs G, Lutzoni F, Debeaupuis J-P, Latgé J-P, Denning DW, Dyer PS, 2005b. Evidence for sexuality in the opportunistic fungal pathogen Aspergillus fumigatus. Current Biology 15, 1242-1248.

Ronquist F, Huelsenbeck JP, 2003. MrBayes 3: Bayesian phylogenetic inference under mixed models. Bioinformatics 19, 1572-1574.

Santos JM, Correia VG, Phillips AJL, 2010. Primers for mating-type diagnosis in Diaporthe and Phomopsis: their use in teleomorph induction in vitro and biological species definition. Fungal Biology 114, 255-270.

Seidl V, Seibel C, Kubicek CP, Schmoll M, 2009. Sexual development in the industrial workhorse Trichoderma reesei. Proceedings of the National Academy of Sciences of the United States of America 106, 13909-13914.

Stamatakis A, Ludwig T, Meier H, 2005. RAxML-III: a fast program for maximum likelihood-based inference of large phylogenetic trees. Bioinformatics 21, 456-463.

Tsui CK-M, DiGuistini S, Wang Y, Feau N, Dhillon B, Bohlmann J, Hamelin RC, 2013. Unequal recombination and evolution of the mating-type (MAT) loci in the pathogenic fungus Grosmannia clavigera and relatives. G3: Genes $\mid$ Genomes|Genetics 3, 465-480.

Turgeon BG, Yoder OC, 2000. Proposed nomenclature for mating type genes of filamentous ascomycetes. Fungal Genetics and Biology 31, 1-5. 
Wada R, Maruyama J-i, Yamaguchi H, Yamamoto N, Wagu Y, Paoletti M, Archer DB, Dyer PS, Kitamoto K, 2012. Presence and functionality of mating type genes in the supposedly asexual filamentous fungus Aspergillus oryzae. Applied and Environmental Microbiology 78, 2819-2829.

Wilken PM, Steenkamp ET, Hall TA, de Beer ZW, Wingfield MJ, Wingfield BD, 2012. Both mating types in the heterothallic fungus Ophiostoma quercus contain MAT1-1 and MAT1-2 genes. Fungal Biology 116, 427-437.

Yamaoka Y, Masuya H, Chung W-H, Goto H, To-Anun C, Tokumasu S, Zhou X, Wingfield M, 2008. The teleomorph of Leptographium yunnanense, discovered in crosses among isolates from Thailand, China, and Japan. Mycoscience 49, 233-240.

Yin M, Duong TA, Wingfield MJ, Zhou X, de Beer ZW, 2015. Taxonomy and phylogeny of the Leptographium procerum complex, including Leptographium sinense sp. nov. and Leptographium longiconidiophorum sp. nov. Antonie Van Leeuwenhoek 107, 547-563.

Yun S-H, Berbee ML, Yoder OC, Turgeon BG, 1999. Evolution of the fungal self-fertile reproductive life style from self-sterile ancestors. Proceedings of the National Academy of Sciences of the United States of America $\mathbf{9 6}$, $5592-5597$.

Zipfel RD, De Beer ZW, Jacobs K, Wingfield BD, Wingfield MJ, 2006. Multi-gene phylogenies define Ceratocystiopsis and Grosmannia distinct from Ophiostoma. Studies in Mycology 55, 75-97. 